This PDF is a selection from an out-of-print volume from the National Bureau of Economic Research

Volume Title: Marriage, Family, Human Capital, and Fertility

Volume Author/Editor: Theodore W. Schultz, editor

Volume Publisher: Journal of Political Economy 82(2), Part II, April 1974

Volume URL: http://www.nber.org/books/schu74-2

Publication Date: 1974

Chapter Title: Household and Economy: Toward a New Theory of Population and Economic Growth

Chapter Author: Marc Nerlove

Chapter URL: http://www.nber.org/chapters/c3689

Chapter pages in book: (p. $200-221)$ 


\title{
Household and Economy: Toward a New Theory of Population and Economic Growth
}

\section{Marc Nerlove}

\author{
University of Chicago
}

It is somewhat unusual to begin the treatment of a subject with a warning against attaching too much importance to it; but in the case of economics, such an injunction is quite as much needed as explanation and emphasis of the importance it really has. It is characteristic of the age in which we live to think too much in terms of economics, to see things too predominantly in their economic aspect.... There is no more important prerequisite to clear thinking in regard to economics itself than is recognition of its limited place among human interests at large. [Frank H. KNIGHT, 1933 (1965)]

\section{Introduction: Malthus Revised}

Malthus, in essays published in 1798 and 1830, and the classical economists combined a very simple model of family decision makingprocreation without bound except possibly by "a foresight of the difficulties attending the rearing of a family... and the actual distresses of some of the lower classes, by which they are disabled from giving the proper food and attention to their children" (Malthus 1970, p. 89)with an equally simple model of the operation of the economy. According to the latter, a high level of capital accumulation induced by a high level of profits-representing the difference between output and the rent of land (natural resources) and wages-permitted a continual increase in output and population, albeit at the cost of resort to land of increasingly

I am indebted to Gary S. Becker, Glen Cain, Richard B. Freeman, Margaret G. Reid, and $T$. W. Schultz for discussions concerning the subject of this paper and for comments on a related paper. Virginia Thurner contributed valuable editorial advice. This research was supported by a grant from the Rockefeller Foundation to the University of Chicago for the study of the economics of population and family decision making. 
poorer quality; it did not, as the result of the model of family decisionmaking, lead to a rising standard of living for most people. Thus, the classical economists achieved a very simple model of economic growth and development (Baumol 1970, pp. 13-21). Modern growth theorists in the tradition of Solow (1956) and Swan (1956) have developed theories of economic growth based on far more elaborate theories of the economy, but few theories of population growth and family decision making have gone much beyond the Malthusian model (Pitchford 1973, pp. 1-10). Although natural-resource constraints may be readily incorporated through the device of diminishing returns to scale in the variable factors (Swan 1956, pp. 340-42), it is a constant proportional rate of population growth, perhaps aided and abetted by exogenous technological progress, that essentially drives the mechanism. Discussions of the optimal rates of population growth or level of population do often attempt to integrate an endogenously determined population in the model. But none, to my knowledge, have examined the feedback from changes in the economy and changes in the relative prices and costs which families face when they decide how many children they will have and what they will invest in those children's health, nutrition, or education, although Pitchford (1973) does discuss the costs of and returns to population control at the macro level.

In recent years, the recognition, crucial to the understanding of longterm growth, that much investment which occurs in the economy is made in human beings rather than in physical capital and that fertility itself is shaped in important ways by economic considerations has led to renewed interest in the economics of the household decisions. In that type of unit, not only decisions about fertility, but also those related to investments in human capital, consumption and savings, migration, laborforce participation, and, in a sense, marriage itself, are made.

With this in mind, in Section 2 I briefly and critically describe the fundamental elements of the largely static theory of household production and choice. This theory was developed in its modern form by Gary Becker (1965) and others, but most of its essentials originated in the much earlier work of Margaret Reid (1934), and it owes a good deal to Wesley Mitchell's seminal observations in his essay (1912) on "The Backward Art of Spending Money." Section 3 concludes this paper with some speculations on how the "new home economics" may be integrated in a theory of economic growth and development through an understanding of the way in which investment in human capital increases the value of human time and thus changes over time the resource constraints and the relative costs and prices which "households" face in their decisions on the number and quality of children they attempt to produce. The question as to whether this constitutes a true economic explanation of the so-called demographic transition, and thus a revision of the Malthusian tradition, is basically an empirical one and is left open. 


\section{The "New Home Economics": Summary and Critique}

In its most unadorned form, economics is the theory of allocation of limited resources among competing ends in order to maximize satisfactions (or utility), subject to the constraints imposed by limitations in the availability of the resources required to achieve those ends. Various elaborations and accretions are necessary to accommodate this central theoretical core to the dynamics of choices made sequentially over time and in the presence of uncertainty regarding future constraints and future preferences. At several points I shall have more to say about our present failure to reach successful accommodations in our underlying theory in these directions, as well as about our even more important limitations as economists to cope with the whole complex of issues raised by intergenerational transfers, within society as an ongoing concern, and particularly within the family.

The first element in the new home economics is the utility function to be maximized. Its form and its arguments (i.e., what variables determine its level) are obviously crucial in determining the choices which result from its maximization. But whose utility function is it that is maximized in connection with choices pertinent to marriage, children, consumption of commodities, work and leisure, and investment in all forms of capital? Considering the household as already formed, much of the theoretical underpinning rests on what I have called elsewhere the "Chicago model" (Nerlove 1972b). ${ }^{1}$

The "Chicago utility function," if I may call it that, has several key characteristics. First, it does not involve nonmarket goods or physical commodities and purchasable services as we usually think of them in economics, but its arguments are abstract goods composed of a number of "attributes" which must themselves be produced within the household (Becker 1965; Lancaster 1966; Muth 1966). The importance of this characteristic of the utility function is that it leads directly to the key questions of household technology and the composition of different types of market goods and services and physical commodities, in terms of attributes contributing to satisfactions. This, indeed, is the point made forcefully by Muth (1966) and recently emphasized by Michael and Becker (1972). Earlier (1947), Leontief pointed out that the theory of consumer behavior as then developed, although of great generality, lacked content to the extent that it gave no clue to the types of relations to be expected among different categories of goods.

The assumption of the existence of general categories of needs, different from demands for particular individual commodities,

\footnotetext{
${ }^{1}$ At this conference, Jacob Mincer objected to this and said that the model should really be called the "Morningside Heights" model; however, force of habit leads me to persist in this terminology.
} 
but still specific enough to be clearly distinguishable from each other, is basic to the man-in-the-street idea of consumers' demand. One speaks of the desire for food as existing behind and separately from the particular demand for bread, apples, or Lobster à la Newburg. This need for food is at the same time spoken of as something clearly distinguishable from the similarly general needs for clothing or, say, for shelter, each of the latter also thought of as existing separately although manifested through the particular demands for one-family houses, apartment flats, or woolen suits and raincoats. [Leontief 1947, p. 371]

Strotz (1957), in his introduction of the notion of a utility tree and in his later (1959) discussion with Gorman, attempted to give more empirical content to the theory of consumer demand in precisely this way, although he interpreted his results in terms of a "budgeting" process. An important aspect of the household production model, including time and market-purchasable goods, as introduced by Becker (1965), Lancaster (1966), and Muth (1966), is precisely, as Muth points out, that it does yield "a utility function which is weakly separable when viewed as a function of commodities purchased on the market" (Muth 1966, p. 700). While it is true, in a sense, that many conclusions of the "new home economics" could be derived directly from Strotzian utility trees and other specializing assumptions, the home-production aspect of the Chicago function lends an intuitive insight and empirical content which are lacking in the more abstract formulation. It suggests a more direct look at the technology of processes within the household and particularly at how such processes use household time and nonpurchased inputs in addition to market-purchasable commodities. Indeed, the supposed differences in the time intensity of the production of household goods give much of the content to recent applications of the "new home economics" to the problems of fertility and human capital formation. ${ }^{2}$ I return to this point in Section 3 where I speculate on how the increasing value of human time works through a Chicago utility function/household-production model to alter the behavior of generations through time.

A second key characteristic of the Chicago utility function is that it is just that: one utility function-the welfare of the children and other members of the family is assumed to enter the utility function of a single decision maker (not always the husband and father!), thus obviating the assumption of a "family utility function" with all the concomitant

${ }^{2}$ Unfortunately, to date relatively little attention has been paid to the implications of the household production model for the more general composition of consumption. Time and market-purchasable-commodity intensities do differ greatly for different types of consumption (e.g., drinking beer or going to a concert), and the new home economics has implications going beyond fertility and human capital formation (see, however, Michael [1972]). 
problems of social utility functions in general. It is perhaps not entirely accurate to identify this position too closely with Chicago; it should perhaps be called the "Samuelsonian finesse." Samuelson (1956) writes:

Where the family is concerned the phenomenon of altruism inevitably raises its head: if we can speak at all of the indifference curves of any one member, we must admit that his tastes and marginal rates of contribution are contaminated by the goods that other members consume. These ... external consumption effects are the essence of family life.... Such problems of home economics are, abstractly conceived, exactly of the same logical character as the general problem of government and social welfare. [P. 9]

... if within the family there can be assurmed to take place an optimal reallocation of income so as to keep each member's dollar expenditure of equal ethical worth, then there can be derived for the whole family a set of well-behaved indifference contours relating the totals of what it consumes: the family can be said to act as if it maximizes such a group preference function. [P. 21]

The problem with the Samuelsonian finesse, however, is that it assumes a fixed family membership, and a great deal of what the Chicago utility function is designed to explain is how that family composition gets determined. This requires much more than Samuelson allows for in his formulation. When, for example, are children members of the family, and thus codeterminers of the utility function, and when are they just arguments in the utility function determined for the family not including them? The full internalization argued by T. W. Schultz (1972b) seems a necessary addition to the argument. Yet, for this to be true, what might be called the "John Donne effect" must be extremely powerful. Casual observation suggests that each individual's concern for others diminishes with distance in both time and space. Yet it may be true under certain restrictive assumptions, as pointed out to me by Assaf Razin, that what might be called pairwise intergenerational internalization (by which I mean full internalization of the utilities of the next succeeding generation by the immediately preceding generation) would lead to essentially the same type of problem as that encountered in the discussions of optimal growth with an infinite horizon.

Morishima (1970, pp. 213-25) presents an extended discussion of some of the more technical issues involved in formulating dynamic utility functions and the conditions under which such functions can be reduced to the sum of discounted utilities of each future generation or at each future point in time, irrespective of the generation involved. In general, these conditions are highly restrictive and closely related to the conditions 
of Strotz (1959) and Gorman (1959) for strong separability of the utility function. But as Koopmans (1967, p. 96) points out, the problem is really in some sense an ethical one:

What is at issue is clearly an intertemporal distribution problem: that of balancing the consumption levels of successive generations, and of successive stages in the life-cycle of a given cohort of contemporaries. The most pertinent decisions-individual, corporate, or governmental-are those that determine investment in physical capital, in human capital, and in research and development. Investments in physical capital, if well made, augment future consumption through an increase in future capital-labor ratios. Investment in human capital raises the quality of labor and, one hopes, of life. Successful research and development augment future capital and labor inputs through the development of better techniques of production.

Even regarded as a strictly behavioral model, pairwise internalization, which seems central to the Chicago utility function, has most important implications for the intergenerational transfers of material wealth and human capital which Knight (1921, pp. 374-75) has so eloquently described as central to the continuity of the social order. ${ }^{3}$ Some of these implications bear on the issues discussed in the next section. Here, however, it seems essential to point out the profound problem in, on the one hand, internalizing all the family members' satisfactions in one utility function and, at the same time, using this same utility function to determine the number and "quality" of the family members themselves. Essentially the problem results from the condensation of a sequential, dynamic set of decisions into a theory of choice based on the maximization of a single, static, timeless utility function. In its most extreme form, the issue of the conceptual adequacy of the approach arises in connection with the application of the new home economics to household formationa formation which in an earlier, less aberrant, and nonconformist era might have been described as "marriage"! Yet marriage, in some sense, remains very much associated with procreation; and the act of marriage, or at least of household formation, is the normal first step in the central process of choice with which the new home economics deals. Where then is the utility function? Can the entire process really be separated into two distinct parts, what the econometrician would call a recursive system? If a fundamental purpose of marriage is the procreation of a couple's own legitimate children, given a society's definition of both marriage and

${ }^{3}$ Indeed, there is good reason to suppose that the reason for many institutions of society is precisely to ensure that the interests of future generations will be adequately guarded by the present. A meaningful theory of intergenerational welfare comparisons has not yet been developed, but such a theory is surely central to our understanding of household decision making and its consequences. 
legitimacy, clearly the process cannot be regarded as recursive. ${ }^{4}$ Again, the static character of the analysis, while not necessarily limiting its usefulness in an empirical sense, introduces a conceptual difficulty of a high order.

The second element in the new home economics is the technology of household production described by a production function or functions and a list of the resources utilized in the processes involved. Typically, following Becker (1965), the inputs are time, perhaps distinguishable by household member (e.g., husband and wife) and market-purchasable commodities. These inputs are used to produce within the household the goods and services that in turn lead to satisfaction. In the simplest form in the economic theory of fertility, two time inputs (the husband's and wife's) and one general market-purchasable commodity are assumed in the household technology to produce three household goods: child numbers, child quality, and a general commodity called "other satisfactions" (Willis 1973; DeTray 1973). In all analyses to date an important further simplification of this basic technological structure has been made: each good entering the utility function is assumed to be produced by a separate independent production process. Jointness in production arises not because of common overhead factors within the household, but because the factor inputs available to the household are subject to overall constraints. ${ }^{5}$ Willis (1973) and DeTray (1973), for example, both assume that child quality per child and child numbers are produced by independent production processes. Each factor separately enters the household utility function in the Willis formulation. The one is simply multiplied with the other to arrive at the final good, child services, which is assumed to enter the household utility function in DeTray's formulation. Both child numbers and child quality are generally assumed to be mother's time-intensive.

This formulation also neglects the sequential and essentially dynamic character of investments in child quality. Casual observation suggests

4 Still, it may be helpful analytically to tackle the problem in a stepwise fashion (see Becker 1973). In part of his work, Becker does consider the division of the gains from marriage, the most important gains being the children, and this is, of course, a matter closely related to the utility function maximized within the marriage.

${ }^{3}$ A partial exception is the work of Michael Grossman (1971; 1972, pp. 74-79). In his analysis Grossman does assume separate production processes but stipulates that the entire amounts of certain factors available to the household must enter each production function as one of its arguments. That is to say, in the standard analysis, if one could separately identify the amount of one factor-say, wife's time-used in a particular activity, one could measure the effect of a unit increase in that input on the output of that activity independently of the overall resource constraint on the wife's time to the household, whereas in Grossman's formulation the overhead factor, say, the family house, cannot in principle be allocated among the activities but must enter fully into each one. Grossman's work, however, still does lack generality in the respect discussed above, since complementarity among final goods cannot be encompassed in his formulation except through the rather Ptolemaic device of introducing some of the final outputs as inputs in the production processes of some of the other outputs. 
that in many societies and families, the eldest son is often the beneficiary of the bulk of the investment in the human capital that takes place in the second generation. Indeed, Sloan's recent work (1971, pp. 31-32) suggests that in poor countries the sex, as well as birth order of a child, may be an important determinant of the infant's survival probabilities, presumably because of the differential investments in health and nutrition that take place within the family rather than for purely genetic reasons.

The restrictiveness of the rather special assumption of separability of productive activities has not been apparent in the basically two-good (child services/other satisfactions) static models usually considered, for what is ruled out is complementarity among different outputs in a multiproduct context. As is well known, under conditions of variable proportions, complementarity (in the sense that the output of one good could be increased without decreasing the output of the other good and without using additional resources) cannot occur if the production unit, in this case the household, is at an optimum and using resources fully. In a three-or-more-product case, however, it is possible for several of the outputs to be complementary with each other, although substitutable jointly against the rest (Hicks 1939 , p. 92) ${ }^{6}$ In the latter case, holding available resources constant, increasing the level of one of the outputs optimally might well involve also increasing another, although clearly a third output level would have to be decreased. One can easily see how restrictive the elimination of complementarity could be in a context involving several dimensions of child quality, for example, health and physical development and intellectual achievement. In a dynamic context such potential complementarities are of even greater significance since there is, for example, some evidence that early underinvestment in nutritional capital may substantially affect the productivity of later investments in intellectual human capital (Berg 1973, pp. 9-12). ${ }^{7}$

The third element in the new home economics is a set of assumptions about the way in which household resources, principally time, can be transformed into market-purchasable commodities to be used in the household production process. Strictly speaking, I suppose one could consider this set of assumptions as part of the general technology of household production and subsumed under the second element of the theory. It is, however, better to treat the matter separately, since most of what is involved concerns the terms upon which household members can enter the labor market, the wages they can earn, and, somewhat secondarily, the prices at which market commodities can be purchased. It is here that the lack of dynamic character of the new home economics cuts most

6 In Hick's argument, substitute the word "outputs" for "factors" and vice versa, and hold the factor of production (his "output") fixed.

${ }^{7}$ It would seem more straightforward and perhaps more desirable in future work to deal with simple forms of multiproduct production functions. For an empirical example, see Eads, Nerlove, and Raduchel (1969). 
deeply into its potential implications for the central problems of fertility and female labor-force participation. The timing and spacing of children, the opportunities for part-time work and accumulation of lifetime labor market experience, and choices as to the amount of education to be invested in early in the life cycle all revolve heavily on the terms under which women can participate in the labor market and thus share in the transformation of the household's time resources into market commodities. The human capital literature (Ben-Porath 1967; Mincer 1970, 1973) is, of course, replete with dynamic analyses of investment in human capital over time and the life-cycle effects of these investments on earnings. But little of this work has entered the more general framework of the "new home economics," particularly as this theory bears on decisions concerning the numbers of children and their timing and spacing within a marriage and the relation of these decisions to the accumulation of other forms of assets. The work of Heckman (1971), Ghez and Becker (1972), and unpublished work of Frank Stafford does, however, represent a notable beginning of the extension of this part of theory into more dynamically relevant realms. ${ }^{8}$ Yet we need to understand far more than we presently do about why the labor market functions so differently for men than for women, the role of institutional constraints, discrimination, and the relation of these to women's choices of occupation and timing of labor-force participation. Once again, the simultaneities of the system severely limit our ability to break out a single segment for proper analysis.

The fourth and final element in the new home economics is the resource constraints facing the household in its production and optimization decisions. Traditionally these constraints are divided into time (husband's and wife's, although often the husband is assumed to devote full time to the market) and "other" nonwage income. While it is universally recognized that some elements of household production and consumptionsleep and food, for example-are in fact inputs into the production-oftime resources, little attention has thus far been paid to the quality of the time resources and of other family resources-both genetic and materialpassed from one generation to the next. Arleen Leibowitz's study of Terman's 1921 sample of California school children, reported in this

${ }^{8}$ Much recent work, however, is dynamic only in the relatively trivial sense of involving maximization over a number of periods of time without uncertainty concerning the values of future values of exogenous constraints to future decisions. This is the sense in which a dynamic programming problem can be turned into an ordinary programming problem of much larger dimensions; apart from the computational difficulties thus introduced, the chief defect of this approach is that it fails to lay bare the sequential nature of the decision-making process in the way, for example, in which the recursive solution to the general dynamic programming problem of Bellman does. In the absence of uncertainty, however, nothing essential is lost by the straightforward multiperiod extension of the basically static framework. When values of future constraints are uncertain, then it does become essential to understand and incorporate the sequential character of the decision process (see Nerlove 1972a). So far this has not been done in the literature of the new home economics. 
volume, bears importantly on the manner in which much human capital is passed from one generation to another, especially to a child of preschool age. The sample is very unrepresentative, but it is instructive, for the investments in her child of a mother's time and the quality of those investments, as measured by her education, are found to affect appreciably later measures of the child's ability and future earning capacity.

The resource constraints facing the household, once it is formed, are, of course, a product of the household formation itself and thus connected with my earlier remarks on the inseparability of this complex of issues, from those of family choice and decision making. But, more important it is in this area that the complex issue of intergenerational transfers figures most prominently. We live, after all,

in a world where individuals are born naked, destitute, helpless, ignorant, and untrained, and must spend a third of their lives in acquiring the prerequisites of a free contractual existence. ... The fundamental fact about society as a going concern is that it is made up of individuals who are born and die and give place to others; and the fundamental fact about modern civilization is that it is dependent upon the utilization of three great accumulating funds of inheritance from the past, material goods and appliances, knowledge and skill, and morale. Besides the torch of life itself, the material wealth of the world, a technological system of vast and increasing intricacy and the habituations which fit men for social life must in some manner be carried forward to new individuals born devoid of all these things as older individuals pass out. The existing order, with the institutions of the private family and private property (in self as well as goods), inheritance and bequest and parental responsibility, affords one way for securing more or less tolerable results in grappling with this problem. [Knight 1921, pp. 374-75]

So the apparently simple theoretical construct of a time budget plus other income constraint to the household conceals beneath its serene and mathematically differentiable exterior the central problem of the continuity of society itself. ${ }^{9}$

\footnotetext{
9 Closely connected to the matter of what is inherited from the past and transferred from generation to generation is the problem of how individual tastes and preferences are formed and how they may change over time. I have not mentioned this issue lest I be excommunicated from the economics profession! It is virtually part of the definition of what an economist is that he takes tastes as given, and I sometimes suspect that many of us require all tastes to be identical and assume that all differences among individuals arise from differences in the resource constraints those individuals face. Indeed, one of the consequences of the conjectures and speculations presented in Section 3 is that the tastes and preferences of at least different generations, if not of individuals within each generation, could remain constant while the number of children per family declined over time due to changes in the value of human time induced endogenously.
} 
By themselves the four main elements of the theoretical structure of the new home economics-(1) a utility function with arguments which are not physical commodities but home-produced bundles of attributes; (2) a household production technology; (3) an external labor-market environment providing the means for transforming household resources into market commodities; and (4) a set of household resource constraintsare incapable of yielding a series of well-defined implications about the main problems of household behavior with which we are concerned. It is only a framework within which to think about these problems. Many special additional assumptions, some of which have been mentioned, must be added to the framework to arrive at empirically refutable propositions. Moreover, the nature of the required additional specifications is intimately related to the peculiarities of the particular bodies of data to which the new home economics has been applied. These data range all the way from aggregate time-series data covering long periods of time, to cross-sectional census data for both large and small geographic regions at a point in time and over time, to household and family data based on individual interviews, with and without collection of retrospective information.

If to the key simplification involved in the assumption of separable independent productive processes within the household, one adds the assumptions that young children are highly intensive of the mother's time in comparison with other activities within the home and older children are less intensive, and that for institutional or biological reasons the comparative advantage of the male partner in the acquisition of market-purchasable commodities significantly exceeds that of the female partner, a number of interesting implications of the theory emerge which are tolerably well supported by the empirical evidence so far analyzed. Setting aside for the moment the inadequacy of the observed market wage to measure the cost of a nonworking woman's time, the immediate implication of the theory is that a rise in cost of mother's time for the family will cause a substitution away from time-intensive goods such as children and toward those requiring more inputs of market-purchasable commodities. Indeed, if we further assume momentarily that males are completely specialized in market activities, changes in their wages represent pure income effects for the family, and we do then observe for families with working mothers positive association of family size with income and negative association with female wage rates. To the extent that education serves as a proxy for the relative costs of time which may measure some of these costs less imperfectly, or at least in a fashion different from market wages, similar differences are observed between the effects of male and female educational attainments (Mincer 1963; Nerlove and Schultz 1970; Willis 1973, DeTray 1973; Ben-Porath 1973).

The interpretation of many of the results is somewhat complicated 
by the effects of marriage on the association of the educational attainments of husbands and wives, and by the fact that wives and mothers for the most part specialize entirely in home activities during only varying fractions of their lifetimes. Moreover, the effects of female education seem unexpectedly and puzzlingly nonlinear (Ben-Porath 1973). To illustrate the nature of the difficulty involved, consider the following simple analysis of the effects of assortative mating. We know that men of higherthan-average levels of educational attainment tend to marry women of higher-than-average levels of educational attainment. Suppose, however, that tastes for children differ among the population; women with a high taste for children and a low taste for market-related activities will tend in general to seek and to receive less formal schooling than women with the opposite preference. Presumably a man's taste for children in a society where nearly all men specialize in market-related activities will not be reflected very greatly in his formal schooling. Some effect of the amount of his formal schooling may occur through early marriage, but he will certainly seek a mate with like preferences. Thus, men with a given level of schooling with a high taste for children will tend to marry women with less schooling than the average associated with the level these men have achieved. If, as is common, a husband's educational attainment is associated primarily with permanent income effects within the household, and his wife's is associated primarily with the opportunity cost of time, one can see that the negative effect of the opportunity cost of time as measured this way on fertility will tend to be exaggerated, holding male educational attainment constant, since the difference between the two across couples partly reflects differences in tastes which are unobservable and not included in the statistical analysis (see also T. W. Schultz [1973b, p. S8] for a related comment).

Turning the analysis around, we can ask what implications the new home economics has for female labor-force participation. The new home economics predicts what is perhaps the obvious: the composition of a woman's family is strongly associated with her labor-force participation. Typically, the number of a family's children under the age of 18 and the age of the youngest child are both strong predictors of a woman's laborforce participation. These facts about family composition have been interpreted by Cain (1966), for example, as measures of the opportunity value of a mother's time in the home. Gronau (1973) attempted a detailed and sophisticated analysis of just this proposition, using a subsample of the 1/1000 sample from 1960 United States Census; moreover, he examined the interaction of educational attainment with family composition. Others (Smith 1972; Leibowitz 1972) have documented that highly educated married women participate to a greater extent in the labor force and work more hours when they do work than married women with less schooling. Married women as a group also tend to withdraw 
from the labor force when they have children; this is an implication of the new home economics, on the assumption that children are more female time-intensive than other commodities produced within the home; but the rates at which women with different educational attainments withdraw is not the same. During the child-rearing years, more highly educated women reallocate more hours to household production than do women with less education. Ben-Porath's (1973) finding of a $U$-shaped relation between education and labor-force participation for Israeli women with young children strongly suggests differences in the effects of education at different levels on the relative efficiencies of home and market production and also interactions between female education and child quality. But all of this has been insufficiently explored within the presently existing framework of the new home economics. As Sweet (1968), Nerlove and Schultz (1970), and Hall (1973) have emphasized, educational investments, labor-force participation, and fertility must be viewed, at least partly, as simultaneously determined choices. This is surely one of the most important implications of the new home economics and only partly negated by the latter's currently static character.

Finally, if we regard, as I think we must, the grand problem of the new home economics as the explanation of the demographic transition, that is, the "economic and social processes and family behavior that accounts for the marked decline from very high birth and death rates to modern very low birth and death rates" (T. W. Schultz 1973b, p. S4), the new home economics does have some insights, albeit limited, to offer (O'Hara 1972). Clearly, a high probability of child mortality affects the costs of achieving a given family size, that is, the number of children surviving to a given age. If it is assumed that on the whole parents achieve a greater (discounted) sum of satisfactions the longer a child survives and if declines in mortality result in greater relative increases in the conditional probabilities of survival from earlier ages to successively older ages, declines in mortality should tend, according to the new home economics, to generate a greater demand for children. This need not lead to an increase in births, however, since such declines in mortality lower the cost of child quality relative to the cost of numbers of children. Of course, the net effect must depend on the technology of the production of child numbers and child quality as well as on the relative importance of these in the utility function. These factors, of course, may vary substantially from time to time, culture to culture, and place to place. The elucidation of such effects, however, must surely constitute one of the central challenges to the empirical application of the new home economics. To explore such effects fully, however, requires that the household decision-making process be accommodated in a model of economic growth and development, a subject to which we now turn. 


\title{
3. Household Decision Making and Economic Growth: Speculations and Conjectures
}

\author{
"Would you tell me, please, which way I ought to go from \\ here?" \\ "That depends a good deal on where you want to get to," \\ said the Cat. [Alice's Adventures in Wonderland]
}

In his classic paper on "Diminishing Returns from Investment," Knight (1944) pointed out that "if new investment can be freely directed to all uses, i.e., embodied in all types of productive agents indifferently, it will not be subject to diminishing returns" (p. 33). Moreover, he stressed, as did Marshall before him, the concept of capital in human beings, and that "in the production of laborers the matter of 'quality' is far more important than that of quantity in the crude sense of numbers" (p. 35). Although investment "freely directed" might not be subject to diminishing returns, certainly, under static circumstances, continued investment in any one particular direction ought eventually to result in a declining rate of return. Yet, as T. W. Schultz (1973b) has emphasized, the rate of return appears to have diminished little, if at all, in response to a high level and even accelerated pace of investment in human capital, and, indeed, it may have actually risen (T. W. Schultz 1971, p. 173).

We do not, of course, have any really accurate measure of the extent of investment in human capital as compared with investment in nonhuman capital and in the stock of knowledge through investment in research and development. Yet, there are a number of clues which suggest that the capital stock invested in human beings, even on a per capita basis, has been a steadily growing portion of the total capital stock. T. W. Schultz (1961, p. 73) suggests a rise of the value of the stock of educational human capital embodied in the stock of labor of persons age 14 and older from 18 percent in 1900 of the total educational and physical capital to 30 percent in 1957. These estimates do not include on-the-job training or investments in better health and nutrition. In terms of gross capital formation, Kuznets (1966, p. 243) calculates, on the basis of Schultz's earlier work, a rise in the share of investments in formal education alone from "about $9 \%$ in 1900 to over $38 \%$ in the 1950s." Moreover, for Western countries as a whole, Kuznets (1971) calculates the share of labor has risen from 55 to 75 percent of national income over the same period. These facts, meager as they may be, suggest two significant questions which are germane to the issue with which this paper began, namely, how can the new home economics be integrated into a general theory of economic growth and development in a manner which has some hope, at least, of bearing on the grand question of the demographic transition? These two questions are the following. 
First, what accounts for the failure of the rate of return to investments in human capital, even counting educational investments, to fall, despite a high and accelerating rate of investment in this form of capital relative to other forms? In other words, why does there appear to be a persistent disequilibrium among these rates of return?

Second, quite apart from the possibility of disequilibrium rates of return (even if they are in equilibrium), what effect will increasing human capital investment per capita have on the allocation of resources within the household and what, if any, repercussions will it have for the rate of growth of population and labor force? A number of speculations and conjectures on the answers to these questions follow; they emphasize the role of the increasing value of human time over time and its relation, which is reciprocal, to the increasing level of investment in human beings.

Razin (1969, 1972) showed how, under certain circumstances, the ratio of human to total capital per capita would increase along the optimal growth path of an economy experiencing technical progress. As indicated earlier, T. W. Schultz has emphasized this aspect of the persistant failure of rates of return to investments in human capital to decline. The demand for skills and knowledge embodied in human capital does not decline because of additional investments in the stock of useful knowledge and technique (technological change) which require the continual adaptation and adjustment of the human agent to utilize efficiently this augmented stock and seek out the new sources of investment opportunities which maintain the growth process. But even in the absence of a persistent disequilibrium created by the demand for human capital, it is possible that the rates of return to such investments would fail to fall over time, or fall only slowly, in relation to the rates of return to other forms of investment because of endogenously changing relative cost of investment, that is, changes on the supply side.

One of the most important consequences of the growing "quality" of human beings as reflected in the increased stock of human capital per capita, as pointed out by T. W. Schultz (1973b), is the increasing value of human time per unit of such time. Many of the consequences of the increasing value of time over time are amusingly explored by Linder (1970) in his penetrating study of The Harried Leisure Class. Yet Linder and Schultz fail to note the important link which may exist between the increasing value of human time, due presumably to investment in human capital as well as to investment in other forms of capital and in technological change, and the terms on which investment in human capital takes place. If one assumes, as I think plausible, that children (as regards both quality and quantity) are time-intensive as compared with other goods produced within the home, it follows that unless the increasing investment 
of human capital increases the marginal productivity of a unit of time in the care and rearing of children within the home in an offsetting fashion, increases in the value of time will lead to a shift away from children to less time-intensive activities. To be sure, such a substitution effect may be offset by a strong income effect, but there are still further grounds to suppose that both substitution and income effects will tend to lead to an increase in child quality rather than child numbers.

In a recent note (1973), Becker and Lewis explored the consequences of a simple model of the relation between the quality and quantity of a good (in this case, children) entering the utility function, under the assumption that quality per unit is the same for all units. Increases in either quantity or quality cause the shadow prices of the other to rise and if, as is plausible, the income elasticity for quality is greater than that for quantity, the resulting increase in the shadow price of numbers would reduce the apparent income elasticity for quantity, perhaps even to negative level. Thus, the income effect of the increasing value of human time should, under these circumstances, lead to a substitution of quality for quantity of children, in addition to leading to a substitution away from children altogether to less time-intensive goods. This rests of course, on the premise that the productivity of time in rearing children is unchanged or, at least, not greatly increased. Moreover, the pure price effects are likely to work in the same direction, since it is plausible that quantity is more time-intensive than quality of children per unit of equal quality time and that, indeed, the shadow price of quality is likely to be reduced by increases in the quality of the mother's time input (I refer again to Arleen Leibowitz's paper in this volume).

The investments in child quality referred to earlier take two major forms: (1) sound nutrition and health care, and (2) education, skills, or attitudes conducive to acquisition of further education and skills.

Good nutrition and health care increase youngsters' chances of survival and may also affect their ability to absorb future investments in intellectual capital. To the extent that such investments increase the life span, particularly the span of years over which a person can be economically active, such an increase in quality will raise the return to investments in human capital which sons and daughters may later wish to make in themselves. To the extent that better health and nutrition result in a reduction in child mortality, they increase the satisfactions accruing to parents from other forms of investment which also raise child quality, for the returns to these investments may then be expected to be enjoyed over a longer period of time on average. Increases in longevity, particularly of an individual's economically productive years, increase the amount of human time available without increasing population; such an increase would tend by itself to lower the value of time per unit, but, as we know, 
most of the effects of better health care and nutrition occur in childhood and enhance the quality of a unit of time in later years more than increasing the number of children. On net balance, therefore, I would conjecture that better health and nutrition lower the costs of further investments in human capital relative to those in other forms of capital and increase the returns therefrom.

The second main form which an increase in child quality may take is, as I have stated, through investment in the form of education, skills, or attitudes conducive to later acquisition of further education or skills. Much investment in human capital of this type tends to be time-intensive in the preschool years, although the productivity of a unit of a mother's time, as remarked, may be especially enhanced by a greater stock of human capital embodied in her, so it is not necessarily true that over time, as the result of the increasing value of human time, substitution will tend to occur away from this form of investment. Nonetheless, it is in this area that we might expect some induced "technological innovations" which could economize on a mother's scarce time. Nursery schools, day-care centers, and the proliferation of "educational" toys are perhaps examples. On the whole, then, I think we may conclude that increases in quality of children relative to their numbers take the form of investments in human capital which ultimately have the effect of raising the value of time per unit in the economically active years of adulthood.

For reasons which I feel certain we do not fully understand, but which are due in part to the presence of children's utilities in the utility function of the family to which they belong, parents do desire to bequeath a stock of capital to their children. Since the stock of capital, material and intangible, human and nonhuman, is growing per capita in Western economies, one must assume that parents desire to pass along more than that which they received from their parents, or that institutions in the economy function in such a way as to induce this outcome. Irrespective of the motivation, however, the increasing value of human time must have an effect on the form in which this capital is passed on. As long as rates of return to investments in human capital remain above, or fall more slowly than, the rates of return to investments in other forms of capital, parents will be induced to bequeath a greater part in the form of human capital. Thus, the tendency toward increasing quality of children will be intensified by the bequest motive, despite the opposite tendency, resulting from the increasing cost of time, to invest in bequests which are less time-intensive. But as rates of return tend to equality over time-if they ever do-parents should tend to bequeath less in the form of human capital and more in the form of financial and physical capital. Nonetheless, as long as investment in human capital occurs, the value of a unit of human time will continue to rise with increases in the stock of capital 
per capita, reinforcing the tendency to fewer children of ever-higher quality. Substitution will occur in favor of fewer children of higher quality and perhaps eventually against both quality and quantity of children in favor of commodities and knowledge. The "facts" cited at the beginning of this section, suggesting an increasing portion of total capital formation in this century has occurred in the form of human capital, however, indicate that we may be far from the point at which such substitution begins to take place against children, quality, and quantity combined.

The outlines of a revised Malthusian model begin to emerge, albeit dimly, from the foregoing conjectures and speculations. In this model, the value of human time and changes in that value over time are pivotal, and the limitations imposed by natural resources are mitigated, if not eliminated, by technological progress and increases in the stock of knowledge and of capital, both human and nonhuman. The main link between household and economy is the value of human time; the increased value of human time results in fewer children per household, with each child embodying greater investments in human capital which in turn result in lower mortality and greater productivity in the economically active years. Such greater productivity in turn further raises both the value of a unit of time and income in the subsequent generation and enables persons of that generation to make efficient use of new knowledge and new physical capital. Eventually, rates of return to investments in physical capital, new knowledge, and human capital may begin to equalize, but as long as investment occurs which increases the amount of human capital per individual, the value of a unit of human time must continue to increase. It is not possible to say whether the diminishing ability of a human being to absorb such investment would eventually stabilize the number of children per household and at what level, given the satisfactions parents obtain from numbers of children as well as their quality. Nonetheless, over time the model does predict in rough qualitative fashion declining rates of population growth (perhaps eventually zero rates or even negative rates for a time) and declining rates of infant mortality. These are the main features of the demographic transition.

Much remains to be done if this rough and speculative outline is to be translated into a true integration of the new home economics with the modern theory of economic growth, particularly as the former evolves along more dynamic and empirically relevant lines. First, the model must be mathematized-and it is clear that there are many forms in which this may be accomplished-so that the crucial parameters and behavioral relations may be isolated. These must then be studied empirically, for without quantitative knowledge of the parameters and technologies involved and the key behavioral relations the course of the important variables over time cannot be predicted or compared with past behavior. 
The role of the growth theorist is apparent in the first of these tasks and those of the econometrician and economic historian in the second. Finally, the conceptual foundations of the new home economics, particularly with respect to intergenerational transfers, must be clarified if we are to understand the extent to which actual growth departs from the optimal path, the reasons for such departure, and whether collective action is either desirable or necessary to correct such departures.

I hope this paper represents at least a modest beginning in showing where it is we want to get to, if not a set of directions on which way we ought to go from here. 


\section{Comment}

\section{Zvi Griliches}

Harvard University

I shall divide my comments into two parts, corresponding to Nerlove's discussion of the "new home economics" and the stylized "facts" that appear to be building blocks for a future growth model. I am very much in agreement with Nerlove's exposition of the "new home economics," but I would like to amplify a bit two of his implied criticisms of the state of this theory.

One of the major working assumptions of the theory is the existence of a common family utility function. In his paper in this volume, Gary Becker shows that by introducing the notion of "caring" (or the interdependence of utilities) one can show that the family will behave as if it has a common utility function. This will not do, I think, for the analysis of the empirical phenomena that we are really interested in. What parents care for is not the utility that their children receive, but the utility function that the children have and the resources that they control. Parents care about the consumption basket of their children; they have preferences over actual actions, not just their subjective outcomes. Much of the within-family conflict comes from different evaluations of the same consumption opportunities. For example, since many families appear to subsidize their children's higher education, and since the marginal valuation of family funds may not be the same for different family members, it may pay for the young both to pursue higher education further than appears warranted on straight rate-of-return calculations (somebody else is paying the cost), and to work less hard at it than the donors of the money would have liked them to do. In any case, a common utility function cannot explain either the growth of households or their dissolution, or indicate the point at which it pays for the young to opt out of it. It is probably also not necessary for the analysis of such questions, as is indicated by Becker's model of the marriage market. 
The main shortcoming of the "new home economics" for the analysis of fertility decisions is that it assumes too little. The basic postulates are that children are goods, that all goods are subject to two constraintstime and money-and that children are relatively time-intensive goods. But this does not distinguish children from hi-fi sets! Adding the observation that children tend to use mother's time more than father's does not get us much further. Moreover, given the aims of the theory, this should probably come out as a conclusion, rather than be assumed from the beginning. In any case, the theory focuses on children as a good whose costs have a relatively high time component (particularly mother's time). Thus, any changes that have occurred have to be explained in terms of changes in total marginal cost (money and time) of this good (children) relative to the cost of all other consumption goods. I do not think that this is enough. The theory currently provides one explanation (among several competing ones) of the secular decline in fertility, attributing it to the rising cost of time, but it fails to provide any convincing explanation for the major fertility cycles that we have experienced. As the discussion at this conference made clear, we have no economic explanation yet within the framework of this theory either for the baby boom of the 1950s or the current rather sharp decline in fertility

My belief is that if we want to study the demand for children, we have to put more content into the theory and start asking why do people want to have children; what are the returns and not just the costs of this activity? In terms of the theoretical framework used in this volume, I am looking for shifters of the utility function, or, alternatively, for factors that change the implicit household production function. If we are studying the demand for children rather than for hi-fi sets, we have to ask ourselves what it is about children that distinguishes them from other time-intensive durable goods. Perhaps we should go back to some low-level discussions about the "motives" for having children, along the lines of the discussion of the demand for money in older textbooks. I would distinguish at least three interdependent motives: (1) economic security (current labor and old-age provisions), (2) the production of reciprocal caring, and (3) an attempt at immortality via one's offspring.

The last motive explains the attempts to impose an image on the children (an improved version of our own) and the interest in the actual basket of consumption rather than just the summary state (utility) of their well-being. The returns in terms of the first two motives have been declining secularly, perhaps even faster than the rise in costs implied by the cost-of-time hypothesis. It is my guess that part of the recent sharp decline in fertility stems from the clear recognition on the part of the current childbearing cohort of the relatively low rate of return experienced by their own parents. 
Turning to the last part of Nerlove's paper, I want to take issue with the two stylized facts that appear to be empirical building blocks for his growth model: the constancy of the rate of return to schooling and a persistent disequilibrium reflected in higher rates of return to the investment in human as compared with physical capital. Both Finis Welch and I have to take some blame for popularizing the first "fact" at a time when it was beginning to cease being a "fact." The persistence of relatively high rates of return to schooling through the 1950s and 1960s in the face of rising schooling levels throughout the economy was probably the result of an accidental constellation of forces rather than the expression of an underlying constancy in the economic mechanism. The higher education boom was sustained by three forces: (1) the first round of cohorts to be educated after World War II was a relatively small and declining fraction of the population; (2) the post-World War II baby boom increased greatly the demand for teachers at all levels; and (3) at about the same time the government superimposed on all of this a space-defense-researchand-development boom, heavily human capital-intensive, resulting in a scramble for young, educated talent. Unfortunately, these fortuitous influences have run their course. The educational system has probably reached its longer-run equilibrium level, if it has not overshot it. The space research and development boom is over now, at a time when there is, and will be for the next 5 years or so, an annual wave of an additional one million highly educated workers arriving at the doors of the full-time labor force. The rates of return to schooling have already started falling and will probably fall quite a bit further before supply response catches up with them.

Also, I am not sure that I understand the disequilibrium discussion in Nerlove's paper. First, I know of no study that shows that relevant rates of return, computed in comparable terms, are significantly higher for schooling than for physical investment. The fact that human capital may have been growing faster than physical is no evidence for this proposition, and it does not require it. 